\title{
A previously unknown source of reactor radionuclides in the Baltic Sea, identified by 233, 236, ${ }^{238} \mathrm{U}$ and ${ }^{127,}{ }^{29}$ I multi-fingerprinting
}

Jixin Qiao ( $\nabla_{\text {jiqi@env.dtu.dk ) }}$

Technical University of Denmark

Haitao Zhang

Northwest Institute of Nuclear Technology

Peter Steier

University of Vienna https://orcid.org/0000-0002-6144-2449

Karin Hain

University of Vienna https://orcid.org/0000-0001-5083-1986

Xiaolin Hou

Technical University of Denmark

Vesa-Pekka Vartti

Radiation and Nuclear Safety Authority (STUK) https://orcid.org/0000-0002-6602-5599

Gideon Henderson

University of Oxford

Mats Eriksson

Swedish Radiation Safety Authority

Ala Aldahan

United Arab Emirates University

Goran Possnert

Uppsala University

Article

Keywords: multi-isotopic fingerprints, radioactive sources, 236U, Baltic Sea

Posted Date: August 4th, 2020

DOI: https://doi.org/10.21203/rs.3.rs-49352/v1

License: (a) (i) This work is licensed under a Creative Commons Attribution 4.0 International License.

Read Full License 
Version of Record: A version of this preprint was published at Nature Communications on February 5th, 2021. See the published version at https://doi.org/10.1038/s41467-021-21059-w. 


\section{Abstract}

We present the first application of multi-isotopic fingerprints (i.e., ${ }^{236} \mathrm{U} /{ }^{238} \mathrm{U},{ }^{233} \mathrm{U} /{ }^{236} \mathrm{U},{ }^{236} \mathrm{U} /{ }^{129}$ I and ${ }^{129} I /{ }^{127}$ I) for the discovery of unrevealed radioactive sources. Our data indicate that, besides the reactor signature from the two European reprocessing plants and global fallout signature, there must be a previously undiscovered additional reactor ${ }^{236} \mathrm{U}$ source in the Baltic Sea. This reactor ${ }^{236} \mathrm{U}$ may come from unreported discharges from nuclear research facilities in Sweden, or it may come from accidental leakage from disposal of spent nuclear fuel on the Baltic seafloor, either reported or unreported. Such leakage would indicate potential problems with the safety of seafloor disposal, and may be accompanied by leakage of other radionuclides. The results demonstrate the high sensitivity of the multi-isotopic tracer systems, especially the newly accessible ${ }^{233} \mathrm{U} /{ }^{236} \mathrm{U}$ signature, to distinguish environmental emissions of unrevealed historical or present radioactive releases for nuclear safeguard and emergency preparedness, as well as tracing environmental processes from the releasing sites.

\section{Introduction}

${ }^{236} \mathrm{U}\left(\mathrm{t}_{1 / 2}=2.34 \times 10^{7} \mathrm{y}\right)$ is an isotope of uranium, which is produced by thermal neutron capture of the omnipresent ${ }^{235} \mathrm{U}$ via $(\mathrm{n}, \mathrm{y})$-reactions and through ${ }^{238} \mathrm{U}(\mathrm{n}, 3 \mathrm{n}){ }^{236} \mathrm{U}$ reactions with fast neutrons. Even though a small amount (about $35 \mathrm{~kg}$ in total) of ${ }^{236} \mathrm{U}$ is produced naturally in the Earth's surface environments, ${ }^{236} \mathrm{U}$ is (by mass) the largest secondary product created in nuclear reactors, estimated totally to be an order of $10^{6} \mathrm{~kg}{ }^{1} .{ }^{236} \mathrm{U}$ is a sensitive tracer of deliberate or accidental leakage from the nuclear fuel/waste cycle ${ }^{2-5}$. The known sources of reactor ${ }^{236} \mathrm{U}$, i.e., deliberate releases from the two European reprocessing plants at La Hague, France (LH) and Sellafield, UK (SF) since 1950s, can be traced throughout the North Atlantic and the Arctic water currents ${ }^{6}$. Emissions from other known sources of reactor ${ }^{236} \mathrm{U}$, e.g., the Springfield nuclear facility and the Fukushima accident, are negligible ${ }^{5,7}$.

A significant amount of ${ }^{236} \mathrm{U}$ (estimated at $>1000 \mathrm{~kg}$ ) was also delivered to the Earth's surface environments from the global fallout of atmospheric nuclear weapons testing in the $1950 \mathrm{~s}$ and $1960 \mathrm{~s}^{8}$. This omnipresent fallout source can make identification of unreported sources of reactor ${ }^{236} \mathrm{U}$ challenging, because of methodological difficulties in distinguishing the source of ${ }^{236} U^{9}$. In addition, the ${ }^{236} \mathrm{U} /{ }^{238} \mathrm{U}$ ratio does not provide source information because of ${ }^{238} \mathrm{U}$ of natural origin is ubiquitous.

Reactor ${ }^{236} \mathrm{U}$ could be differentiated from fallout ${ }^{236} \mathrm{U}$ because these sources have different and characteristic ${ }^{233} \mathrm{U} /{ }^{236} \mathrm{U}$ ratios due to different nuclear production mechanisms. ${ }^{233} \mathrm{U}$ was mostly produced during nuclear weapons testing by fast neutrons via ${ }^{235} U(n, 3 n){ }^{233} U$ reactions or directly by ${ }^{233} \mathrm{U}$-fueled devices, whereas almost no ${ }^{233} \mathrm{U}$ is produced in thermal nuclear power reactors or reprocessing plants ${ }^{10}$. Recently ${ }^{233} \mathrm{U}$ measurements at environmental level have become possible ${ }^{10}$. 
The representative ${ }^{233} \mathrm{U} /{ }^{236} \mathrm{U}$ atomic ratio of global fallout from atmospheric nuclear weapons testing was suggested to be $(1.40 \pm 0.12) \times 10^{-210}$. This is several orders of magnitude higher than the ${ }^{233} \mathrm{U} /{ }^{236} \mathrm{U}$ atomic ratio in nuclear reactors, e.g., $1 \times 10^{-7}-1 \times 10^{-6}$ in LH discharges ${ }^{11}$, which agrees well with reactor model calculations ${ }^{12}$. In the Irish Sea, an average ${ }^{233} \mathrm{U} /{ }^{236} \mathrm{U}$ atomic ratio of $(0.12 \pm 0.01) \times 10^{-2}$ has been measured ${ }^{9}$, reflecting a dominant reactor signal released from SF. The use of the ${ }^{233} \mathrm{U} /{ }^{236} \mathrm{U}$ atomic ratio helps better distinguishing the origin of ${ }^{236} \mathrm{U}$ and since being radionuclides of the same element, the ${ }^{233} \mathrm{U} /{ }^{236} \mathrm{U}$ ratio will not be affected during the transport pathway. In addition, the combination of ${ }^{236} \mathrm{U}$ with other radionuclides, e.g. ${ }^{129} \mathrm{I}$, can be useful to trace the transport of ${ }^{236} \mathrm{U}$ from specific source points, e.g., releases from LH and SF ${ }^{13-16}$.

The Baltic Sea is a highly polluted sea, including potentially for anthropogenic radionuclides. It receives radionuclides from global fallout, discharges from the two European reprocessing plants, potentially from the Chernobyl accident, and from any other local sources. In this study, we use a novel combination of three anthropogenic radionuclides $-{ }^{233} \mathrm{U},{ }^{236} \mathrm{U}$, and ${ }^{129}$ I - to identify a previously unknown local source of radionuclide pollution to the Baltic Sea.

\section{Results}

The study area and sampling. The Baltic Sea is a landlocked intracontinental sea in Northern Europe and constitutes one of the largest brackish water environments on Earth with about 80 million inhabitants in the surrounding states ${ }^{17}$. The water exchange of this large brackish estuarine-like water mass with the Kattegat and the North Sea takes place through the narrow and shallow Danish Straits (Figure 1). The driving force for the water circulation is fresh water surplus from river run-off estimated at $473 \mathrm{~km}^{3} \mathrm{yr}^{-1}$ together with "recycled" North Sea inflowing water as Baltic outflow that sum up to a total water exchange rate of $753 \mathrm{~km}^{3} \mathrm{yr}^{-1} 18$. A mean residence time for the $21580 \mathrm{~km}^{3}$ Baltic water volume was estimated to be 29 years which is equivalent to a "half-life" for the water volume of 20 years ${ }^{18}$.

In the investigation presented here, water and sediments samples were collected from the Baltic Sea and related water masses including the western Danish coast in the years 2011-2016 (Table S1 and S2). The water sampling covers mainly the surface distribution (0-5 $\mathrm{m}$ depth), with a few samples from deep water and one riverine water from the Mälaren river, which receives downstream discharges from a nuclear fuel fabrication facility (Westinghouse) in Sweden. In addition to the Baltic Sea water, we analyzed sediment samples to gain some idea about the accumulation trend of the isotopes in the bottom of the Baltic Sea. A more detailed description of the study area and samples can be found in the Methods section.

To facilitate the presentation of results and related discussion, we grouped the sampling locations into five geographical regions (Figure. 1) in the Baltic Sea including 1) KGR: Kattegat-Skagerrak and the region including the Danish west coast nearby the North Sea; 2) DS: Danish Straits including the Belt Seas and the Sound; 3) SBR: South Baltic Sea region including Arkona Basin, Borholm Basin and South Baltic Proper; 4) MBR: Middle Baltic Sea region including Northern Baltic Proper, Western Gotland Basin, Eastern 
Gotland Basin and Gulf of Riga; and 5) NBR: North Baltic Sea region including Archipelago and Åland Sea, Bothnian Sea and Bothnian Bay.

\section{Distribution of ${ }^{236} \mathrm{U}$ concentration and ${ }^{236} \mathrm{U} /{ }^{238} \mathrm{U}$ and ${ }^{233} \mathrm{U} /{ }^{236} \mathrm{U}$ atomic ratios}

The measured ${ }^{236} \mathrm{U} /{ }^{238} \mathrm{U}$ atomic ratios (Table S1, S2) vary within $(5-52) \times 10^{-9}$, with the higher ratios (in the central and northern parts of the Baltic Sea and lower ones in the western parts (Danish Straits, Kattegat/Skagerrak and Danish west coast). The highest value reported here is 6 -fold higher than the average value found in the North Sea in $2010\left((7.6 \pm 3.7) \times 10^{-9}\right)^{19}$.

The distribution patterns (Figure 2) suggest a decline of ${ }^{236} \mathrm{U}$ concentration that is labeled with discharges from LH and SF in the North Sea at the water crossover into the Kattegat and further into the Baltic Sea. However, high ${ }^{236} \mathrm{U}$ concentrations $\left((6-9) \times 10^{7}\right.$ atom/L) are observed in the surface water of the Bothnian Sea and Borthnian Bay, which are comparable to the central North Sea values $\left((3-10) \times 10^{7}\right.$ atom/L) ${ }^{19}$. Compared to the Kattegat-Skagerrak region, the average ${ }^{236} \mathrm{U} /{ }^{238} \mathrm{U}$ atomic ratio in the middle and north Baltic region increases by a factor of 3 , from $(10 \pm 3) \times 10^{-9}$ to $(32 \pm 7) \times 10^{-9}$. This increasing pattern of ${ }^{236} \mathrm{U} /{ }^{238} \mathrm{U}$ ratio points out an additional, likely local, supply of ${ }^{236} \mathrm{U}$ in the Baltic Sea ${ }^{7}$.

${ }^{233} \mathrm{U} /{ }^{236} \mathrm{U}$ atomic ratios obtained here are in the range of $(0.14-0.87) \times 10^{-2}$, with the lower ${ }^{233} \mathrm{U} /{ }^{236} \mathrm{U}$ atomic ratios distributed close to the western parts of the Baltic, including the Danish coast, and the higher ratios in the central Baltic Sea. As the typical ${ }^{233} \mathrm{U} /{ }^{236} \mathrm{U}$ ratio for global fallout is $(1.4 \pm 0.1) \times 10^{-2}$ ${ }^{9}$, the high ${ }^{233} \mathrm{U} /{ }^{236} \mathrm{U}$ in the central Baltic Sea could indicate either strong influence of global fallout or addition from a local source.

\section{Distribution of ${ }^{129} \mathrm{I}$ concentration, ${ }^{129} \mathrm{I} /{ }^{127} \mathrm{I}$ and ${ }^{236} \mathrm{U} /{ }^{129} \mathrm{I}$ atomic ratios}

The measured ${ }^{129} \mathrm{I}$ concentrations $\left((3-232) \times 10^{9}\right.$ atom/L) and ${ }^{129} \mathrm{I} /{ }^{127} \mathrm{I}$ atomic ratios $\left((101-1286) \times 10^{-9}\right)$ in the seawater collected in this work show comparable values and distribution trends as observed in an earlier investigation ${ }^{20}$, with the highest values in the North Sea-Skagerrak-Kattegat which decrease toward the Sound and remain relatively constant in the Baltic Proper. The distributions of ${ }^{129}$ | concentrations and ${ }^{129}\left|{ }^{127}\right|$ atomic ratios indicate that the major source of ${ }^{129} \mid$ in the Baltic Sea are marine discharges from the two nuclear reprocessing plants at LH and SF. The water mass pathways from these plants have been shown to contain appreciable amounts of ${ }^{129} \mathrm{I}$ along the passage to the Baltic Sea ${ }^{21}$.

Aldahan et al. ${ }^{21}$ reported that the average concentration of ${ }^{129} \mathrm{I}$ in the rivers around the Baltic Sea was $3.9 \times 10^{8}$ atom/L, which suggested some minor contribution of ${ }^{129} \mathrm{I}$ from riverine water to the Baltic Sea. The ${ }^{129}$ I concentrations show a larger gradient (two orders of magnitude) compared to the ${ }^{236} \mathrm{U}$ concentrations (15-fold) along the Baltic Sea. ${ }^{236} \mathrm{U} /{ }^{129} \mathrm{I}$ ratios are within the range of $(5-133) \times 10^{-4}$ and 
indicate a reversed geographical distribution compared to ${ }^{129} I$ concentration and ${ }^{129} \mid /{ }^{127} I$ atomic ratio (Figure 2).

\section{Discussion}

\section{Potential sources of uranium and iodine in the Baltic Sea}

The overall sources of uranium and iodine in the Baltic Sea can be summarized as follows:

A) Natural ocean water, with salinity of $35 \%$, which contains about $60 \mu \mathrm{g} / \mathrm{L}$ of ${ }^{127} \mathrm{I}, 3 \mu \mathrm{g} / \mathrm{L}$ of ${ }^{238} \mathrm{U}$, but negligible ${ }^{129} \mathrm{I},{ }^{236} \mathrm{U}$ and ${ }^{233} \mathrm{U}$.

B) Natural fresh water with salinity $<1 \%$ and negligible concentrations of ${ }^{129} \mathrm{I},{ }^{236} \mathrm{U}$ and ${ }^{233} \mathrm{U}$, and lower ${ }^{127}$ I and ${ }^{238} \mathrm{U}$ than seawater $(0.05-10 \mu \mathrm{g} / \mathrm{L}$ for both nuclides).

C) Global fallout from atmospheric nuclear weapons testing, with negligible ${ }^{127}$ I and ${ }^{238} \mathrm{U}$, an average ${ }^{233} \mathrm{U} /{ }^{236} \mathrm{U}$ atomic ratio of $(1.4 \pm 0.2) \times 10^{-2}$, and a surface geographical distribution pattern for ${ }^{236} \mathrm{U}$ and ${ }^{233} \mathrm{U}$ similar to that of ${ }^{137} \mathrm{Cs}$ which is not unusually high in the Baltic region ${ }^{22}$. Earlier studies have estimated ${ }^{236} \mathrm{U}$ concentration (up to $1.4 \times 10^{8}$ atom/L peaking in 1960 s) in surface water of the North Sea to be related to global fallout, which may have been partly masked by discharges from the nuclear reprocessing of $\mathrm{LH}$ and SF 21,22 . In the Baltic Sea, that has an average depth of $55 \mathrm{~m}$, the dilution by vertical dispersion is limited, and a ten times higher concentration is expected for the same inventory, which might mimic higher input. The ${ }^{233} \mathrm{U} /{ }^{236} \mathrm{U}$ atomic ratio of the global fallout contribution is expected to be constant after 1980 when all countries stopped aboveground nuclear bomb tests. Concentration of ${ }^{236} \mathrm{U}$ in river runoff is expected to have reduced over the decades, while the ${ }^{233} \mathrm{U} /{ }^{236} \mathrm{U}$ atomic ratio stays constant.

D) Marine discharges from European nuclear fuel reprocessing plants (including mainly SF and LH), with known ${ }^{236} \mathrm{U}$ and ${ }^{129}$ I source functions ${ }^{23,24}$, but negligible amounts of ${ }^{127} I$ and ${ }^{238} U$. This source dominates the ${ }^{236} \mathrm{U}$ and ${ }^{129} \mathrm{I}$ budget of marine water entering the Skagerrak from the North Sea. Compared to ${ }^{236} \mathrm{U}$, almost no ${ }^{233} \mathrm{U}$ is produced in thermal nuclear reactors, and thus ${ }^{233} \mathrm{U}$ should also be absent from marine discharges of the reprocessing plants.

E) The Chernobyl accident. Pu from Chernobyl has been found in fallout over central Europe ${ }^{25}$ and, as Pu and $U$ are refractory elements transported similarly by atmospheric dispersion, Chernobyl ${ }^{236} \mathrm{U}$ should have been deposited following a similar pattern as Pu isotopes. Consequently, a Chernobyl signal of ${ }^{236} \mathrm{U}$ may be present in river runoff and marine waters. Based on the present understanding of the production mechanisms of ${ }^{233} \mathrm{U}$, it is expected that Chernobyl fallout is not a significant contributor of ${ }^{233} \mathrm{U}$ in this context. 
Waters entering the Baltic Sea from the North Sea have ${ }^{236} U /{ }^{238} U$ and ${ }^{233} U /{ }^{236} U$ atomic ratios set by the balance of reprocessing discharge and global fallout ${ }^{9,19}$. As they distribute in the Baltic and mix with waters from various rivers, these ratios can be altered by addition from local sources of ${ }^{236} \mathrm{U}$ and ${ }^{233} \mathrm{U}$ (and minor ${ }^{238} \mathrm{U}$ in river waters). Removal of uranium from Baltic water will not alter the ratios. The increase in ${ }^{236} \mathrm{U} /{ }^{238} \mathrm{U}$ observed within the Baltic Sea points clearly to a local source of this anthropogenic radionuclide.

\section{${ }^{236} \mathrm{U}$ source identification via binary mixing}

The concentration of ${ }^{238} \mathrm{U}(\mathrm{Fig} .3 \mathrm{~A})$ demonstrates a strong positive correlation $\left(\mathrm{R}^{2}=0.91\right)$ with salinity. The intercept corresponds to the average riverine input with a ${ }^{238} \mathrm{U}$ concentration of $0.33 \pm 0.05 \mu \mathrm{g} / \mathrm{L}$, which falls in the range $(0.2-0.7 \mu \mathrm{g} / \mathrm{L})$ of ${ }^{238} \mathrm{U}$ for some rivers in the Baltic Sea region ${ }^{26}$. There is more scatter in the ${ }^{238} \mathrm{U}$ concentration for low salinities, which might be attributed to differences in regional riverine input. I-129 also shows a positive linear correlation $\left(R^{2}=0.69\right)$ with salinity (Fig. 3B), but strong scatter occurs at the high salinity end. This trend can be attributed to the mixing of ${ }^{129} \mathrm{I}$ enriched North Sea coast water with ${ }^{129}$ I depleted North Atlantic water in the Kattegat-Skagerrak region (Fig. 1 A). The ${ }^{238} \mathrm{U}$ and ${ }^{129}$ I trends with salinity suggest that their concentrations in the Baltic Sea are mainly controlled by the saline water input from the North Sea via Kattegat-Skagerrak, mixing with river-waters in the basin.

Both the ${ }^{236} \mathrm{U} /{ }^{238} \mathrm{U}$ and ${ }^{236} \mathrm{U} /{ }^{129} \mathrm{I}$ atomic ratios increase with the decreasing salinity as water mix in the interior of the Baltic Sea. The ${ }^{236} \mathrm{U} /{ }^{238} \mathrm{U}$ ratio increases by a factor of 3 , while the ${ }^{236} \mathrm{U} /{ }^{129} \mathrm{I}$ ratio increases from an average of $(8 \pm 2) \times 10^{-4}$ in the Kattegat-Skagerrak region, corresponding to reprocessing derived ${ }^{236} \mathrm{U}$ and ${ }^{129}$, to $1 \times 10^{-2}$ in the central Baltic Sea. Both ratios indicate addition of ${ }^{236} \mathrm{U}$ from a local source. The difference in increases between the two ratios can be explained by the presence of ${ }^{238} \mathrm{U}$ and possibly ${ }^{129} \mathrm{I}$ in that local source in addition to ${ }^{236} \mathrm{U}$. If the source does not contain any ${ }^{129} \mathrm{I}$, the 10 -fold increase in ${ }^{236} \mathrm{U} /{ }^{129}$ I suggests that ca. $90 \%$ of ${ }^{236} \mathrm{U}$ in the central Baltic Sea is from local sources. If the source does contain ${ }^{129} \mathrm{I}$, the portion of ${ }^{236} \mathrm{U}$ derived locally must be still larger.

To understand the source terms of ${ }^{236} \mathrm{U}$ in the Baltic Sea, a binary mixing model is applied with two respective end members representing ${ }^{236} \mathrm{U}$ input from the North Sea and freshwater input via river runoff. Parameters for the first end member representing the North Sea water entering from the west Baltic Sea are well defined by previous studies (Table S3) ${ }^{19,27}$. The deviation of the observed ${ }^{236} \mathrm{U} /{ }^{238} \mathrm{U}$ atomic ratio from the binary mixing (line L1, Fig. 4A) between the North Sea water and an assumed freshwater end member containing no ${ }^{236} \mathrm{U}$ (neither ${ }^{233} \mathrm{U}$ ) reflects additional ${ }^{236} \mathrm{U}$ sources besides North Sea water. The spatial distribution of deviations in the ${ }^{236} \mathrm{U} /{ }^{238} \mathrm{U}$ atomic ratio allow locating the additional ${ }^{236} \mathrm{U}$ source (Figure S2). The distribution pattern in Figure S2 is compatible with the hypothesis of additional riverine ${ }^{236} \mathrm{U}$ input from the north Baltic region, which has most river runoff. 
Nevertheless, it is challenging to define the ${ }^{236} \mathrm{U} /{ }^{238} \mathrm{U}$ ratio of the riverine input to the Baltic because some global fallout may still be washing from the land surface. The ${ }^{236} \mathrm{U} /{ }^{238} \mathrm{U}$ and ${ }^{236} \mathrm{U} /{ }^{129}$ I ratios therefore do not directly indicate whether the excess ${ }^{236} \mathrm{U}$ is only from global fallout, or from an additional, previously undiscovered, source that has directly released ${ }^{236} U$ to the Baltic Sea.

\section{Application of ${ }^{233} \mathrm{U} /{ }^{236} \mathrm{U}$ atomic ratio for ${ }^{236} \mathrm{U}$ source identification}

If we assume that the excess ${ }^{236} \mathrm{U}$ originates only from global fallout, the ${ }^{236} \mathrm{U} /{ }^{238} \mathrm{U}$ atomic ratio of the riverine input in the best-fit binary mixing is $6 \times 10^{-8}$ (line L, Fig. 4A). However, there is a clear deviation of the observation from the model for ${ }^{233} \mathrm{U} /{ }^{236} \mathrm{U}$ atomic ratios (Fig. 5A). A subgroup of samples from the Kattegat-Skagerrak reveal a relatively stable ${ }^{233} \mathrm{U} /{ }^{236} \mathrm{U}$ atomic ratio of $0.2 \times 10^{-2}$ (blue dash-dotted line in Fig. 5) independent of ${ }^{236} \mathrm{U} /{ }^{238} \mathrm{U}$ and salinity. This behavior can be explained by assuming an end member of North Sea water with ${ }^{233} \mathrm{U} /{ }^{236} \mathrm{U}$ atomic ratio $=0.2 \times 10^{-2}$ (a mixed signal of global fallout plus nuclear reprocessing) and salinity $35 \%$, which is mixed with natural uranium or water with neither ${ }^{236} \mathrm{U}$ nor ${ }^{233} \mathrm{U}$. This feature shows the notable impact of nuclear reprocessing from SF and $\mathrm{LH}$ in the region.

On the other hand, a cluster of samples with the majority from the middle and north Baltic Sea region indicate a typical ${ }^{233} \mathrm{U} /{ }^{236} \mathrm{U}$ atomic ratio of $0.5 \times 10^{-2}$ (the green dash-dotted line in Fig. 5), uncorrelated with both ${ }^{236} \mathrm{U} /{ }^{238} \mathrm{U}$ and salinity. This cluster lies significantly below the binary mixing model $\mathrm{L}$, indicating an additional local ${ }^{236} \mathrm{U}$ sources besides the global fallout, which is characterized by low ${ }^{233} \mathrm{U} /{ }^{236} \mathrm{U}$ atomic ratio. A low ${ }^{233} \mathrm{U} /{ }^{236} \mathrm{U}$ atomic ratio is typical for releases from nuclear reactors, thereby we assume such a reactor-related source of ${ }^{236} \mathrm{U}$ with negligible ${ }^{233} \mathrm{U}$ in the following.

About two-third of the anthropogenic uranium observed in the middle and north Baltic Sea region seems to originate from this third source (Equation (1)), indicating a strong contribution of ${ }^{236} \mathrm{U}$ without ${ }^{233} \mathrm{U}$, e.g. a nuclear reactor sourced ${ }^{236} \mathrm{U}$.

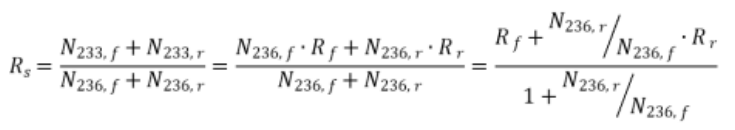

Where $R_{s}, R_{f}$ and $R_{r}$ represent respectively the ${ }^{233} \mathrm{U} /{ }^{236} \mathrm{U}$ atomic ratio of the Baltic seawater, global fallout and nuclear reactor; $N_{233,} f$ and $N_{233, r}$ refer to the atomic number of ${ }^{233} \mathrm{U}$ from global fallout and reactor, respectively; ${ }^{N_{236, f}}$ and ${ }^{236, r}$ refer to the atomic number of ${ }^{236} \mathrm{U}$ from global fallout and reactor, respectively. Therefore, ${ }_{236, r}^{N_{2}} / N_{236, f}=\frac{R_{f}-R_{s}}{R_{s}-R_{r}}$. With $R_{s}=0.5 \times 10^{-2}, R_{f}=1.4 \times 10^{-2}$ and $R_{r}=0.12 \times 10^{-2}$, we obtain that the ${ }^{236} \mathrm{U}$ contribution from our assumed reactor source is 2.4 times that of global fallout.

To locate this additional reactor ${ }^{236} \mathrm{U}$ source, we apply another binary mixing line L2 (Figure $4 \mathrm{~A}$ ) of the North Sea water with riverine water, the latter carrying global fallout which accounts for $1 /(1+2.4)$ of the average ${ }^{236} \mathrm{U}$ concentration in the Baltic Sea $\left((6.0 \pm 1.7) \times 10^{7}\right.$ atom/L). Thus, the riverine endmember is characterized by salinity $=0,{ }^{238} \mathrm{U}=0.4 \mu \mathrm{g} / \mathrm{L},{ }^{236} \mathrm{U}=1 /(1+2.4) \times\left(6 \times 10^{7}\right)=2 \times 10^{7}$ atom/L, and ${ }^{236} \mathrm{U} /{ }^{238} \mathrm{U}$ 
atomic ratio $=2 \times 10^{-8}$. The excesses of ${ }^{236} \mathrm{U} /{ }^{238} \mathrm{U}$ atomic ratio from the mixing curve $\mathrm{L} 2$ and their spatial distribution are demonstrated in Figure 6. The data indicate that the extra reactor ${ }^{236} \mathrm{U}$ source input is not from places where salinity is particularly low or where there are rivers, but in the middle and north basins of the Baltic Sea which is probably linked to direct releases of ${ }^{236} \mathrm{U}$ into these locations.

\section{Properties of the ${ }^{236} \mathrm{U}$ unknown source}

To identify the source of the excess ${ }^{236} \mathrm{U}$, the order of magnitude of ${ }^{236} \mathrm{U}$ inventories and fluxes must be estimated. It should be noted this calculation is based only on our data on surface waters, and a precise interpretation will require substantially more data, and to account for many different effects such as vertical distribution of ${ }^{236} \mathrm{U}$ in the Baltic water columns and on the scavenging of uranium into the sediment (especially in the anoxic regions).

The median salinity of the Baltic Sea seawater analyzed here is about $8.3 \%$ (comparable to the reported value of $8.6 \%$ or the Baltic outflow water ${ }^{18}$ ), meaning that the ratio of seawater to riverine water is 1:4. An average excess of $6 \times 10^{7}$ atom/ $L^{236} \mathrm{U}$ in riverine water is obtained based on the deviation of the ${ }^{236} \mathrm{U}$ concentration from L1 in samples from NBR (Figure S2). The volume of the Baltic Sea of 21700 $\mathrm{km}^{328}$ with $80 \%$ riverine water corresponds to $400 \mathrm{~g}$ of ${ }^{236} \mathrm{U}$. Taking into account that ca. $71 \%$ (i.e., $\left.N_{236, r} / N_{236, f}=2.4\right)$ of this excess ${ }^{236} \mathrm{U}$ is from the additional reactor source ( $\left.280 \mathrm{~g}\right)$ as discussed above, the remainder $(\sim 120 \mathrm{~g})$ is related to global fallout.

It is estimated that a total inventory of $1000 \mathrm{~kg}$ of anthropogenic ${ }^{236} \mathrm{U}$ was distributed via global fallout during the 1950s and 1980s mainly on the Northern Hemisphere ${ }^{7}$. Considering the surface area of the Baltic Sea of $3.77 \times 10^{5} \mathrm{~km}^{2}$ (without the catchment area) in comparison to the Northern Hemisphere (half of the Earth's surface area, i.e. $5.10 \times 10^{8} \mathrm{~km}^{2}$ ), then the total ${ }^{236} \mathrm{U}$ deposition from direct global fallout is estimated as $1.5 \mathrm{~kg}$.

However, when considering the 29-year mean residence time of Baltic seawater, then most of the $1.5 \mathrm{~kg}$ ${ }^{236} \mathrm{U}$ was transported out after 60 years, leaving behind $0.19 \mathrm{~kg}$. In addition, some particle-associated ${ }^{236} \mathrm{U}$ fraction from global fallout might be incorporated into the Baltic sediment ${ }^{29}$. Therefore, the above estimation of $120 \mathrm{~g}$ remaining ${ }^{236} \mathrm{U}$ in the Baltic seawater from global fallout (using salinity data) seems justified.

Emissions from the Chernobyl accident may be an additional ${ }^{236} \mathrm{U}$ source in the Baltic Sea, yet it is difficult to be identified. Nuclear dumping and/or nuclear installations around the Baltic countries are also possible source candidates. As marked in Fig. 1, there are many nuclear installations in surrounding Baltic countries, but there is limited documentation about the ${ }^{233} \mathrm{U}$ and ${ }^{236} \mathrm{U}$ release records from these installations (Table S4) ${ }^{11}$. Data on ${ }^{236} \mathrm{U}$ is available from Westinghouse during $1998-2017$, with a total reported release of $1.06 \times 10^{6} \mathrm{~Bq}$ of ${ }^{236} \mathrm{U}$, equal to $0.44 \mathrm{~g}$. In addition, we measured two seawater samples collected in Mälaren River (Table S2), which receives waste discharges from the Westinghouse facility. 
The results show that the ${ }^{236} \mathrm{U} /{ }^{238} \mathrm{U}$ ratios is at the level of $2 \times 10^{-8}$, which is comparable with the seawater samples collected in the central Baltic Sea. The river water shows a ${ }^{233} \mathrm{U} /{ }^{236} \mathrm{U}$ atomic ratio of $(0.18 \pm 0.05) \times 10^{-2}$, a signature of reactor material.

The amount of $0.44 \mathrm{~g}$ of ${ }^{236} \mathrm{U}$ released from the Westinghouse installation is negligible compared to the above estimated $280 \mathrm{~g}$ of the unknown reactor source in the Baltic Sea. For the Mälaren river, the ${ }^{238} \mathrm{U}$ concentration was measured to be $1.5 \pm 0.1 \mu \mathrm{g} / \mathrm{L}$ in this work, together with a flux of $166 \mathrm{~m}^{3} / \mathrm{s}^{28}$, it means an input of $0.1 \mathrm{~g} / \mathrm{yr}$ of ${ }^{236} \mathrm{U}$, which is negligible also.

Another candidate we assume is reactor fuel, dumped into the sea; the atomic ratio of ${ }^{236} \mathrm{U} /{ }^{238} \mathrm{U}$ can be as high as $1 \times 10^{-2}$ in conventional nuclear reactors, which would require only $27 \mathrm{~kg}$ of dumped/dissolved fuel (a commercial nuclear reactor contains $\sim 100000 \mathrm{~kg}$ of fuel). ${ }^{235} \mathrm{U}$ enrichment in reactor fuel is $3 \%$ for light-water reactors, up to $10 \%$ for thermal gas-cool reactors and up to $20 \%$ for fast reactors ${ }^{30}$. The concentration will be even higher in the core of a nuclear reactor for marine applications, where enriched or highly enriched ${ }^{235} \mathrm{U}$ is used; the Russian submarine cores reportedly contain some 50 to $200 \mathrm{~kg}$ of ${ }^{235} \mathrm{U}^{31}$. The former Soviet Union (USSR) was accused for dumping radioactive waste in the Baltic Sea, yet it is not possible to assess the dumped amount ${ }^{32,33}$.

The geographical distribution of ${ }^{236} \mathrm{U} /{ }^{238} \mathrm{U}$ atomic ratio in surface seawater of central Baltic Sea shows high values nearby the Swedish coast close to Stockholm, where a nuclear research company Studsvik AB, Nyköping (100 km south of Stockholm), Sweden, has been in operation since 1950s. It was reported that during 1959 and 1961,64 tons of radioactive waste with total radioactivity of $14.8 \mathrm{GBq}$ were dumped into the coastal area nearby Studsvik ${ }^{34}$. Our measurement on some sediment samples from the Studsvik area show very high ${ }^{236} \mathrm{U}$ content $\left((2.02 \pm 0.12) \times 10^{13}\right.$ atom $\left./ \mathrm{kg}\right)$, which is three orders of magnitude higher than sediment collected from the North Baltic Sea region (Table S2). The ${ }^{233} \mathrm{U} /{ }^{236} \mathrm{U}$ atomic ratio $\left((0.36 \pm 0.05) \times 10^{-2}\right)$ for the Studsvik sediment clearly indicates a higher contribution of reactor input compared to the other five sediments collected in the Baltic Sea with ${ }^{233} \mathrm{U} /{ }^{236} \mathrm{U}$ ratios between $0.59 \times 10^{-2}$ to $0.83 \times 10^{-2}$.

Even though the release of ${ }^{236} \mathrm{U}$ from Studsvik is not well documented due to its low specific radioactivity, it is not surprising that waste discharges from Studsvik contain ${ }^{236} \mathrm{U}$. The high ${ }^{236} \mathrm{U}$ levels in the sediment samples measured most likely originate from scavenging of waterborne ${ }^{236} \mathrm{U}$ from liquid waste discharges by particles into the sediment. Waste dumping/discharges in the Studsvik area are our most plausible candidate for the excess ${ }^{236} \mathrm{U}$ in the Baltic Sea.

\section{Methods}

Detailed description of the study area and sampling. The Baltic Sea features three major basins, the Bothnian Bay, the Bothnian Sea and the Baltic Proper. The two northerly basins (Bothnian Bay and 
Bothnian Sea) are characterized by low salinity water mass (1-3 \%o and 3-7 \%o, respectively) and rather weak vertical salinity stratifications, although strong thermoclines usually develop during the summer 35 . The Bothnian Sea represents a large reservoir of brackish water mass that can be divided into two layers blocked by a weak halocline around a depth of $60 \mathrm{~m}$. The long term circulation of the Bothnian Sea water is dominated by an estuary circulation where the bottom dense waters can be traced as surface water in the Baltic Proper ${ }^{36}$. The Baltic Proper is the largest basin in the Baltic Sea, permanently stratified in the central part with a strong halocline around a depth of $75 \mathrm{~m}$ separating the surface water (salinity 7-8 \%o) from the deep water (salinity 9-20\%) and a long-term cyclonic current circulation pattern ${ }^{37}$. Water exchange in the Baltic Proper happens through renewing of the deep water during extreme inflow events from the Kattegat. The water mass circulation is further associated with outflow of surface water to the Kattegat and inflow of fresher surface waters from the Bothnian Sea, the Gulf of Finland and the Gulf of Riga (Figure 1).

Water samples analysed in the present investigation were collected via different cruises during 20112016. Samples of 2011 were obtained from GEOTRACES cruise on board of research vessel R/V Oceania. Samples from 2013-2014 were collected through the environmental monitoring program for Helsinki Commission (HELCOM). Samples from 2015 were collected on board the research vessel Argos, operated by the marine division of the Swedish Metrological and Hydrological Institute (SMHI). Samples from 2016 were obtained from the Radiation and Nuclear Safety Authority (STUK), Finland, through sampling cruise COMBINE 2 on the research vessel R/V Aranda. One riverine water sample from Mälaren river (in Sweden: $59.33^{\circ} \mathrm{N}, 18.04^{\circ} \mathrm{E}$ ) was also sampled for the radioisotope analyses, as this river receives downstream discharges from a nuclear fuel fabrication facility (Westinghouse) in Sweden.

Five surface $(0-2 \mathrm{~cm})$ sediments in the middle and north parts of Baltic region were collected (Figure 1 and Table S2) during the COMBINE 2 cruise in 2016. One sediment sample collected outside Studsvik in Bergasundet, Bergas strait $\left(58.75^{\circ} \mathrm{N}, 17.40^{\circ} \mathrm{E}\right)$ in 2014, which was obtained by pooling 25 sediment plugs $(0-10 \mathrm{~cm})$ and homogenized at Swedish Radiation Safety Authority (SSM). The Bergasundet, Bergas strait was the drainage area of the nuclear research facility (Studsvik). Details of the sampling campaigns and location of samples are summarized in Table S1, S2 and Figure 1.

Standards and reagents. Uranium standard solution $\left(1.000 \mathrm{~g} / \mathrm{L}\right.$ in $\left.2 \mathrm{~mol} / \mathrm{L} \mathrm{HNO}_{3}\right)$ was purchased from NIST (Gaithersburg, MD), which was used after dilution as a standard for the ICP-MS measurement to quantify ${ }^{238} \mathrm{U}$ in seawater. All reagents used in the experiment were of analytical reagent grade and prepared using ultra-pure water $(18 \mathrm{M} \Omega \cdot \mathrm{cm})$. UTEVA resin $(100-150 \mu \mathrm{m}$ particle size) was purchased from Triskem International, Bruz, France and packed in 2-mL Econo-Columns $(0.7 \mathrm{~cm}$ i.d. $\times 5 \mathrm{~cm}$ length, BioRad Laboratories Inc., Hercules, CA) for the chemical purification of uranium isotopes.

\section{Analytical methods for determination of ${ }^{238} \mathrm{U},{ }^{236} \mathrm{U},{ }^{233} \mathrm{U},{ }^{127} \mathrm{I}$ and ${ }^{129} \mathrm{I}$. The concentration of ${ }^{238} \mathrm{U}$ and ${ }^{127} \mathrm{I}$} in seawater was measured by ICP-MS (X Series", Thermo Fisher Scientific, Waltham, MA) after 10-50 times dilutions with $0.5 \mathrm{M} \mathrm{HNO}_{3}$ and $0.1 \mathrm{M} \mathrm{NH}_{3} \cdot \mathrm{H}_{2} \mathrm{O}$, respectively. The ICP-MS instrument was equipped with an Xt-skimmer core and a concentric nebuliser under hot plasma conditions. The typical operational 
conditions of the instrument have been given elsewhere ${ }^{38}$. Indium (as $\operatorname{lnCl}_{3}$ ) was used as an internal standard and $0.5 \mathrm{~mol} / \mathrm{L} \mathrm{HNO}_{3}$ solution was used as a washing solution between consecutive assays.

The radiochemical method for ${ }^{233} \mathrm{U}$ and ${ }^{236} \mathrm{U}$ determination in seawater was applied according to Qiao et al. ${ }^{39}$. In short, uranium in each seawater sample (0.8-10 L) was co-precipitated with $\mathrm{Fe}(\mathrm{OH})_{3}$, followed by purification with a 2-mL UTEVA column. A 100- $\mu \mathrm{L}$ aliquot of $U$ eluate from the column separation was taken for measurement of ${ }^{238} \mathrm{U}$ by ICP-MS to evaluate the analytical chemical yields by dividing the values in the original samples. The remaining fraction was prepared as target for the AMS measurement of ${ }^{236} \mathrm{U} /{ }^{238} \mathrm{U}$ and ${ }^{233} \mathrm{U} /{ }^{236} \mathrm{U}$. For sediments, 5-10 g of each dried sample was ashed overnight at $450{ }^{\circ} \mathrm{C}$ in a muffle oven and leached with $100 \mathrm{~mL}$ of aqua regia on a hotplate for 30 minutes at $150{ }^{\circ} \mathrm{C}$ and then 2 hours at $200^{\circ} \mathrm{C}$. A $100-\mu \mathrm{L}$ aliquot was taken from the leachate for directly measurement of ${ }^{238} \mathrm{U}$ by ICPMS, which was used to calculate the original ${ }^{238} \mathrm{U}$ concentrations in the sediment sample. The remaining leachate was processed following the same procedure (i.e., $\mathrm{Fe}(\mathrm{OH})_{3}$ co-precipitation and UTEVA column separation) as for seawater samples. The AMS measurement was carried out at the 3-MV tandem accelerator facility VERA (Vienna Environmental Research Accelerator) at the University of Vienna, Austria. The detailed procedure for the sample preparation and AMS measurement of ${ }^{233} U$ and ${ }^{236} U$ has been reported elsewhere ${ }^{40}$.

For the determination of ${ }^{129} \mathrm{I}$ in seawater, $100 \mathrm{ml}$ of sample was transferred a separation funnels. $2.0 \mathrm{mg}$ of ${ }^{127} \mathrm{I}$ carrier (prepared using iodine crystal purchased from Woodward company, USA, with a ${ }^{129} \mathrm{I} /{ }^{127} \mathrm{I}$ ratio of $2 \times 10^{-14}$ ), $500 \mathrm{~Bq}$ of ${ }^{125} \mathrm{I}^{-}$tracer and $0.5 \mathrm{~mL}$ of $0.5 \mathrm{~mol} / \mathrm{L} \mathrm{Na}_{2} \mathrm{~S}_{2} \mathrm{O}_{5}$ solution were added to the funnel, and then the $\mathrm{pH}$ of the solution was adjusted to $1-2$ using $3 \mathrm{~mol} / \mathrm{L} \mathrm{HNO}_{3}$ to convert all iodine species to iodide. With addition of $20-50 \mathrm{~mL}$ chloroform $\left(\mathrm{CHCl}_{3}\right)$ and 2-5 mL $1.0 \mathrm{~mol} / \mathrm{L} \mathrm{NaNO}_{2}$, iodide was oxidized to $\mathrm{I}_{2}$ and extracted to $\mathrm{CHCl}_{3}$ phase by shaking. The extraction procedure was repeated three times to extract all iodine. The $\mathrm{CHCl}_{3}$ phases were combined to a new funnel, $20 \mathrm{~mL} \mathrm{H} \mathrm{H}_{2} \mathrm{O}$ and $0.3-0.5 \mathrm{~mL}$ $0.05 \mathrm{~mol} / \mathrm{L} \mathrm{Na}_{2} \mathrm{~S}_{2} \mathrm{O}_{5}$ solution was added to the funnel to reduce $\mathrm{I}_{2}$ in chloroform phase to iodide and back-extracted iodine into water phase. This extraction and back extraction were repeated once for further purification.

The separated iodine (in iodide form) in a small volume $(5-7 \mathrm{~mL}$ ) was transferred to a centrifuge tube, 1.0 $\mathrm{mL}$ of $0.5 \mathrm{~mol} / \mathrm{L} \mathrm{AgNO}_{3}$ solution and $1 \mathrm{~mL}$ of $3.0 \mathrm{~mol} / \mathrm{L} \mathrm{HNO}_{3}$ were added to form Agl precipitate. The Agl precipitate was separated using centrifugation at $3500 \mathrm{rpm}$ for 3-5 min, and washed in sequence using $10 \mathrm{~mL} 3 \mathrm{~mol} / \mathrm{L} \mathrm{HNO}_{3}$ and two aliquots of $10 \mathrm{~mL}$ deionized water to remove possibly formed $\mathrm{Ag}_{2} \mathrm{SO}_{3}$ and $\mathrm{Ag}_{2} \mathrm{SO}_{4}$ which are soluble in acidic solution. The precipitate was transferred to a $1.5 \mathrm{~mL}$ centrifuge tube. ${ }^{125} \mathrm{I}$ in the precipitate was measured using a Nal gamma detector for calculating the chemical yield of iodine. The prepared Agl precipitate in small tube was dried at $70^{\circ} \mathrm{C}$ and weighed, The dried precipitate was ground to fine powder and mixed with five times by mass of niobium powder (325 mesh, Alfa Aesar, Ward Hill, MA), which was finally pressed into a copper holder using a pneumatic press (Zhenjiang Aode Presser Instruments Ltd.). ${ }^{129} \mid{ }^{127}$ I atomic ratios in the prepared targets were measured 
by the 5 MV AMS system at the Tandem Laboratory, Uppsala University. The standard used in the measurement was the NIST-SRM-4949c ${ }^{129}$ I. All samples, blanks and standards were measured for 6 cycles and 5 minutes per sample in each cycle. A detailed description of AMS system and measurement of ${ }^{129}$ I has been reported elsewhere ${ }^{41}$. It should be noted that only the samples collected in 2015 by research vessel Argos were analysed for ${ }^{129} \mathrm{I}$. Other samples were not feasible for ${ }^{129} \mathrm{I}$ analysis, since the samples have been acidified before receiving, resulting in loss of iodine due to its high volatility in acidic conditions.

\section{Declarations}

\section{Acknowledgements}

J. Q. is grateful to all colleagues in the Radioecology and Tracer Studies Section, Department of Environmental Engineering, Technical University of Denmark and Professor Robin Gloser at VERA, University of Vienna. The authors also wish to thank Danish Navy, STUK, GEOTRACES, SSM and SMHI (Argos cruise) for sample collection. A. A. acknowledges the UPAR funding from the UAEU.

\section{Author contributions}

J. Q. initiated and coordinated the study, wrote manuscript, performed chemical analysis for uranium and made data evaluation. H. Z. performed chemical analysis for iodine. K. H and P. S performed AMS measurement for uranium. A.A. and G. P. coordinated AMS measurement for iodine. H. Z., G. H., X. H., V. V., A.A. and M. E. contributed to sample collection. G. H. and P. S. have valuable input to the outline of the discussion. All contributed to interpretation and manuscript reviewing.

\section{Competing interests}

The authors declare no competing interests.

\section{Additional information}

Supporting information includes Tables S1-S4 and Figure S1, which is available online.

Correspondence and request for materials should be addressed to J. Q.

\section{References}

1. Steier, P. et al. Natural and anthropogenic ${ }^{236} \mathrm{U}$ in environmental samples. Nucl. Inst.and Methods Phys. Res. B 266, 2246-2250 (2008).

2. Pollington, A. D., Kinman, W. S., Hanson, S. K. \& Steiner, R. E. Polyatomic interferences on high precision uranium isotope ratio measurements by MC-ICP-MS: applications to environmental sampling for nuclear safeguards. J. Radioanal. Nucl. Chem. 307, 2109-2115 (2016). 
3. Hedberg, P. M. L., Peres, P., Fernandes, F. \& Renaud, L. Multiple ion counting measurement strategies by SIMS- A case study from nuclear safeguards and forensics. J. Anal. At. Spectrom. 30, 2516-2524 (2015).

4. Ranebo, Y., Hedberg, P. M. L., Whitehouse, M. J., Ingeneri, K. \& Littmann, S. Improved isotopic SIMS measurements of uranium particles for nuclear safeguard purposes. J. Anal. At. Spectrom. 24, 277287 (2009).

5. Bu, W. et al. Development and application of mass spectrometric techniques for ultra-trace determination of ${ }^{236} \mathrm{U}$ in environmental samples-A review. Anal. Chim. Acta 995, 1-20 (2017).

6. Christl, M. et al. A depth profile of uranium-236 in the Atlantic Ocean. Geochim. Cosmochim. Acta 77, 98-107 (2012).

7. Qiao, J. et al. Anthropogenic ${ }^{236} \mathrm{U}$ in Danish seawater: global fallout versus reprocessing discharge. Environ. Sci. Technol. 51, 6867-6876 (2017).

8. Sakaguchi, A. et al. First results on ${ }^{236} \mathrm{U}$ levels in global fallout. Sci. Total Environ. 407, 4238-4242 (2009).

9. Hain, K. et al. ${ }^{233} \mathrm{U} /{ }^{236} \mathrm{U}$ signature allows to distinguish environmental emissions of civil nuclear industry from weapons fallout. Nat. Commun. 11, (2020).

10. Steier, P. et al. The actinide beamline at VERA. Nucl. Instruments Methods Phys. Res. Sect. B Beam Interact. with Mater. Atoms 458, 82-89 (2019).

11. HELCOM MORS Discharge database. https://helcom.fi/baltic-sea-trends/data-maps/databases/.

12. Naegeli, R. E. Calculation of the Radionuclides in PWR Spent Fuel Samples for SFR Experiment Planning. Sandia National Laboratories http://prod.sandia.gov/techlib/accesscontrol.cgi/2004/042757.pdf (2004).

13. Casacuberta, N. et al. First ${ }^{236} \mathrm{U}$ data from the Arctic Ocean and use of ${ }^{236} \mathrm{U} /{ }^{238} \mathrm{U}$ and ${ }^{129} \mathrm{I} /{ }^{236} \mathrm{U}$ as a new dual tracer. Earth Planet. Sci. Lett. 440, 127-134 (2016).

14. Castrillejo, M. et al. Tracing water masses with ${ }^{129} \mathrm{I}$ and ${ }^{236} \mathrm{U}$ in the subpolar North Atlantic along the GEOTRACES GA01 section. Biogeosciences Discuss. 1-28 (2018) doi:10.5194/bg-2018-228.

15. Casacuberta, N. et al. Tracing the Three Atlantic Branches Entering the Arctic Ocean With ${ }^{129}$ I and ${ }^{236}$ U. J. Geophys. Res. Ocean. 123, 6909-6921 (2018).

16. Wefing, A. M., Christl, M., Vockenhuber, C., Rutgers van der Loeff, M. \& Casacuberta, N. Tracing Atlantic Waters Using ${ }^{129} \mathrm{I}$ and ${ }^{236} \mathrm{U}$ in the Fram Strait in 2016. J. Geophys. Res. Ocean. 124, 882-896 (2019).

17. Jakobs, G. Spatial and seasonal distribution of methane and its microbial oxidation in the water column of the central Baltic Sea. (University of Rostock, 2014).

18. Dahlgaard, H. Baltic ${ }^{137}$ Cs outflow through the Danish Straits indicates remobilisation. (2003).

19. Christl, M., Casacuberta, N., Lachner, J., Herrmann, J. \& Synal, H. A. Anthropogenic 236 U in the North Sea - A Closer Look into a Source Region. Environ. Sci. Technol. 51, 12146-12153 (2017). 
20. Yi, P., Aldahan, A., Hansen, V., Possnert, G. \& Hou, X. L. lodine isotopes $\left({ }^{129} I\right.$ and $\left.{ }^{127} I\right)$ in the baltic proper, kattegat, and skagerrak basins. Environ. Sci. Technol. 45, 903-909 (2011).

21. Aldahan, A., Kekli, A. \& Possnert, G. Distribution and sources of 1291 in rivers of the Baltic region. J. Environ. Radioact. (2006) doi:10.1016/j.jenvrad.2006.01.003.

22. Aoyama, M., Hirose, K. \& Igarashi, Y. Re-construction and updating our understanding on the global weapons tests ${ }^{137}$ Cs fallout. J. Environ. Monit. 8, 431-438 (2006).

23. Christl, M. et al. Reconstruction of the ${ }^{236} \mathrm{U}$ input function for the Northeast Atlantic Ocean: Implications for ${ }^{129} \mathrm{I} /{ }^{236} \mathrm{U}$ and ${ }^{236} \mathrm{U} /{ }^{238}$-based tracer ages. J. Geophys. Res. Ocean. 120, 7282-7299 (2015).

24. Castrillejo, M. et al. Unravelling 5 decades of anthropogenic ${ }^{236} \mathrm{U}$ discharge from nuclear reprocessing plants. Sci. Total Environ. 717, 137094 (2020).

25. Ketterer, M. E., Hafer, K. M. \& Mietelski, J. W. Resolving Chernobyl vs. global fallout contributions in soils from Poland using Plutonium atom ratios measured by inductively coupled plasma mass spectrometry. J. Environ. Radioact. 73, 183-201 (2004).

26. Andersson, P. S., Wasserburg, G. J., Chen, J. H., Papanastassiou, D. A. \& Ingri, J. 238U-234U and ${ }^{232} \mathrm{Th}^{230} \mathrm{Th}$ in the Baltic Sea and in river water. Earth Planet. Sci. Lett. 130, 217-234 (1995).

27. Christl, M. et al. First data of Uranium-236 in the North Sea. Nucl. Instr. Meth. B 294, 530-536 (2013).

28. Wikipedia. No Title. https://www.wikipedia.org/.

29. Salbu, B. \& Lind, O. C. Radioactive particles released into the environment from nuclear events. Actin. Nanoparticle Res. 335-359 (2011) doi:10.1007/978-3-642-11432-8.

30. Gupta, C. Material in nuclear energy applicaitons. (Taylor \& Francis Group, 1989).

31. Reistad, O. \& Olgaard, P. L. Russian nuclear power plants for marine applications. NKS-138 (2006).

32. Yablokov, A. V. Radioactive waste disposal in seas adjacent to the territory of the Russian Federation. Mar. Pollut. Bull. 43, 8-18 (2001).

33. Nielsen, S. P. et al. The radiological exposure of man from radioactivity in the Baltic Sea. Sci. Total Environ. 237-238, 133-141 (1999).

34. IAEA. Inventory of radioactive waste disposals at sea. IAEA-TECDOC-1105 vol. 4 (1999).

35. Wullf, F., Stigebrandt, A. \& Rahm, L. Nutrient Dynamics of the Baltic Sea. Ambio 19, 126-133 (1990).

36. Myrberg, K. \& Andrejev, O. Modelling of the circulation, water exchange and water age properties of the Gulf of Bothnia. Oceanologia 48, 55-74 (2006).

37. Yi, P. et al. ${ }^{129}$ I in the Baltic Proper and Bothnian Sea: application for estimation of water exchange and environmental impact. J. Environ. Radioact. 120, 64-72 (2013).

38. Qiao, J., Hou, X., Roos, P. \& Miró, M. Rapid and simultaneous determination of neptunium and plutonium isotopes in environmental samples by extraction chromatography using sequential injection analysis and ICP-MS. J. Anal. At. Spectrom. 25, 1769 (2010). 
39. Qiao, J., Hou, X., Steier, P., Nielsen, S. \& Golser, R. Method for ${ }^{236}$ U Determination in Seawater Using Flow Injection Extraction Chromatography and Accelerator Mass Spectrometry. Anal. Chem. 87, 7411-7417 (2015).

40. Qiao, J., Hain, K. \& Steier, P. First dataset of ${ }^{236} \mathrm{U}$ and ${ }^{233} \mathrm{U}$ around Greenland coast: a 5 -year snapshot (2012-2016). Chemoshpere 257, 127185 (2020).

41. Zhou, W. et al. The $3 \mathrm{MV}$ multi-element AMS in Xi'an, China: Unique features and preliminary tests. Radiocarbon 48, 285-293 (2006).

\section{Figures}

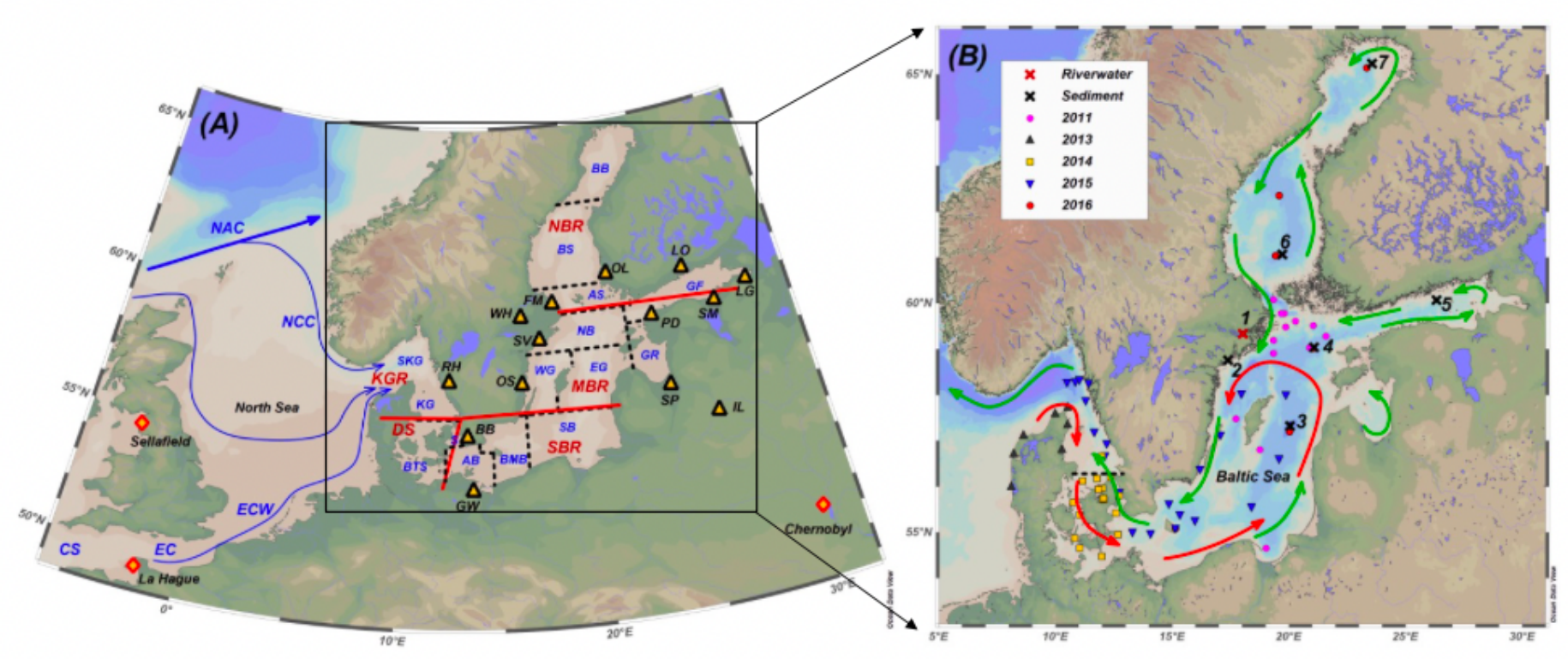

\section{Figure 1}

Overview of schematic circulation water mass in North Sea-Baltic Sea region (A) and sampling stations in this work as well as nuclear installations around the Baltic Sea (B). The symbols in (A) are CS: Celtic Sea; EC: English Channel; ECW: English Channel Waters; NAC: North Atlantic Current; NCC: Norwegian Coastal Current; BB: Bothnian Bay; BS: Bothnian Sea; AS: Archipelago and Åland Sea; GF: Gulf of Finland; NB: Northern Baltic Proper; WG: Western Gotland Basin; EG: Eastern Gotland Basin; GR: Gulf of Riga; SB: Sourth Baltic Proper; BMB: Bornholm Basin; AB: Arkona Basin; S: The Sound; BTS: Belt Sea; KG: Kattegat; SKG: Skagerrak; KGR: Kattegat-Skagerrak region including the Jutland west coast nearby the North Sea; DS: Danish Straits including the Belt Seas and the Sound; SBR: South Baltic Sea region including Arkona Basin, Borholm Basin and South Baltic Proper; MBR: Middle Baltic Sea region including Northern Baltic Proper, Western Gotland Basin, Eastern Gotland Basin and Gulf of Riga; and NBR: North Baltic Sea region including Archipelago and Åland Sea, Bothnian Sea and Bothnian Bay) Nuclear installations including: RH: Ringhals NPP; BB: Barseback NPP; GW: Greifswald NPP; OS: Oskarshamn NPP; SV: Studsvik AB site; WH: Westinghouse Electric Sweden AB; FM: Forsmark NPP; OL:Olkiluoto NPP; LO: Loviisa NPP; LG: 
Leningrad NPP; IL: Ignalina NPP; SM: Sillamäe site; PD: Paldiski site; SP: Salaspils research reactor; The stations marked with cross in (B) are either riverwater or sediment samples (1-Marelene river water, 2Studsvik sediment, 3-sediment BY15; 4-sediment LL17; 5-sediment LL3a; 6-sediment EB1; 7-sediment $\mathrm{CVI})$, all the other samples are seawaters collected in different years during 2011-2016 as marked with different symbols. Red arrows refer to bottom water movement and green arrows refer to surface water movement.
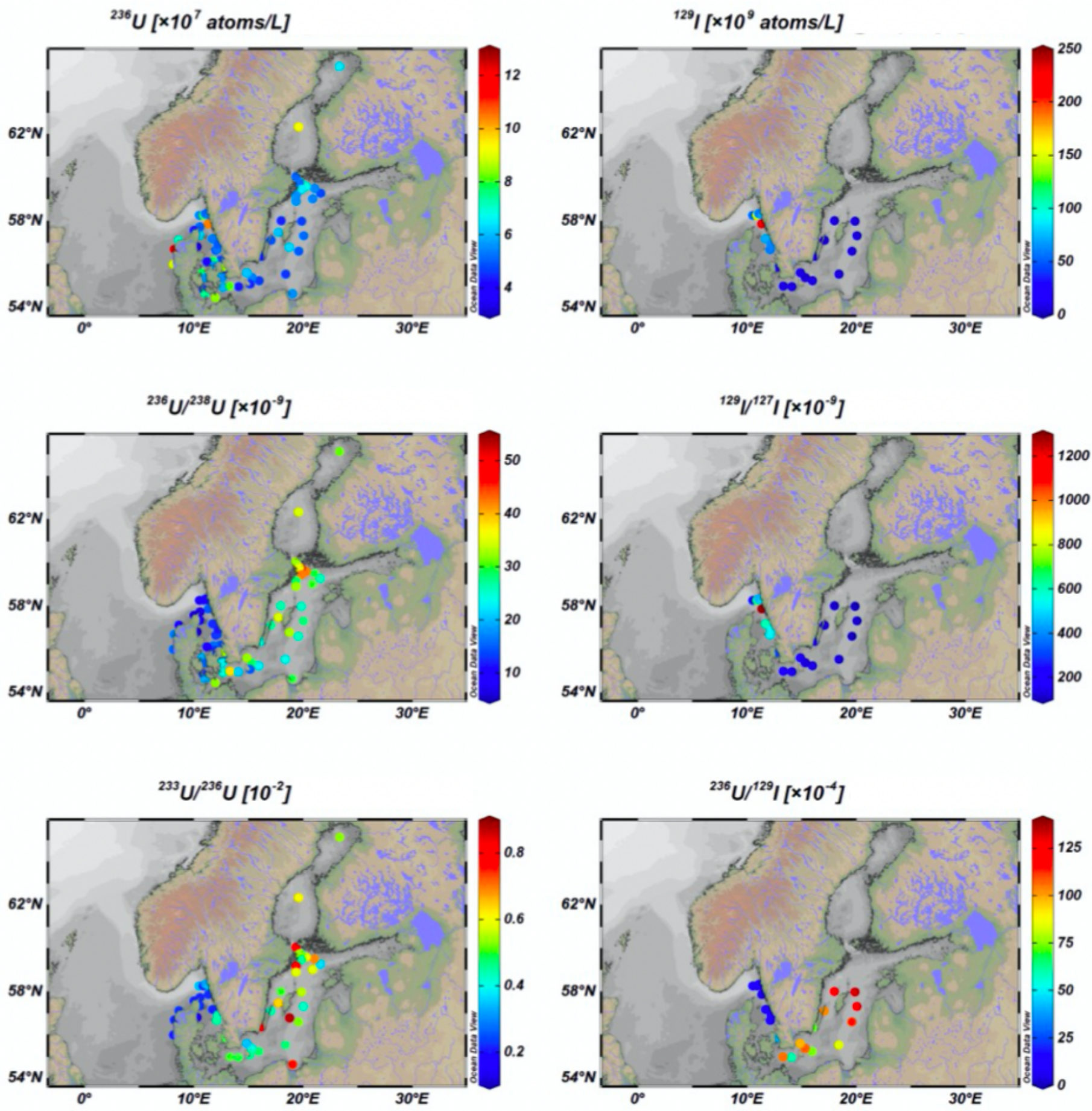

Figure 2 
Distribution of $236 \mathrm{U}$ and $129 \mathrm{I}$ concentrations, and 236U/238U, 129I/127I, 233U/236U and 236U/129I atomic ratios in the Baltic Sea surface water during 2011-2016.
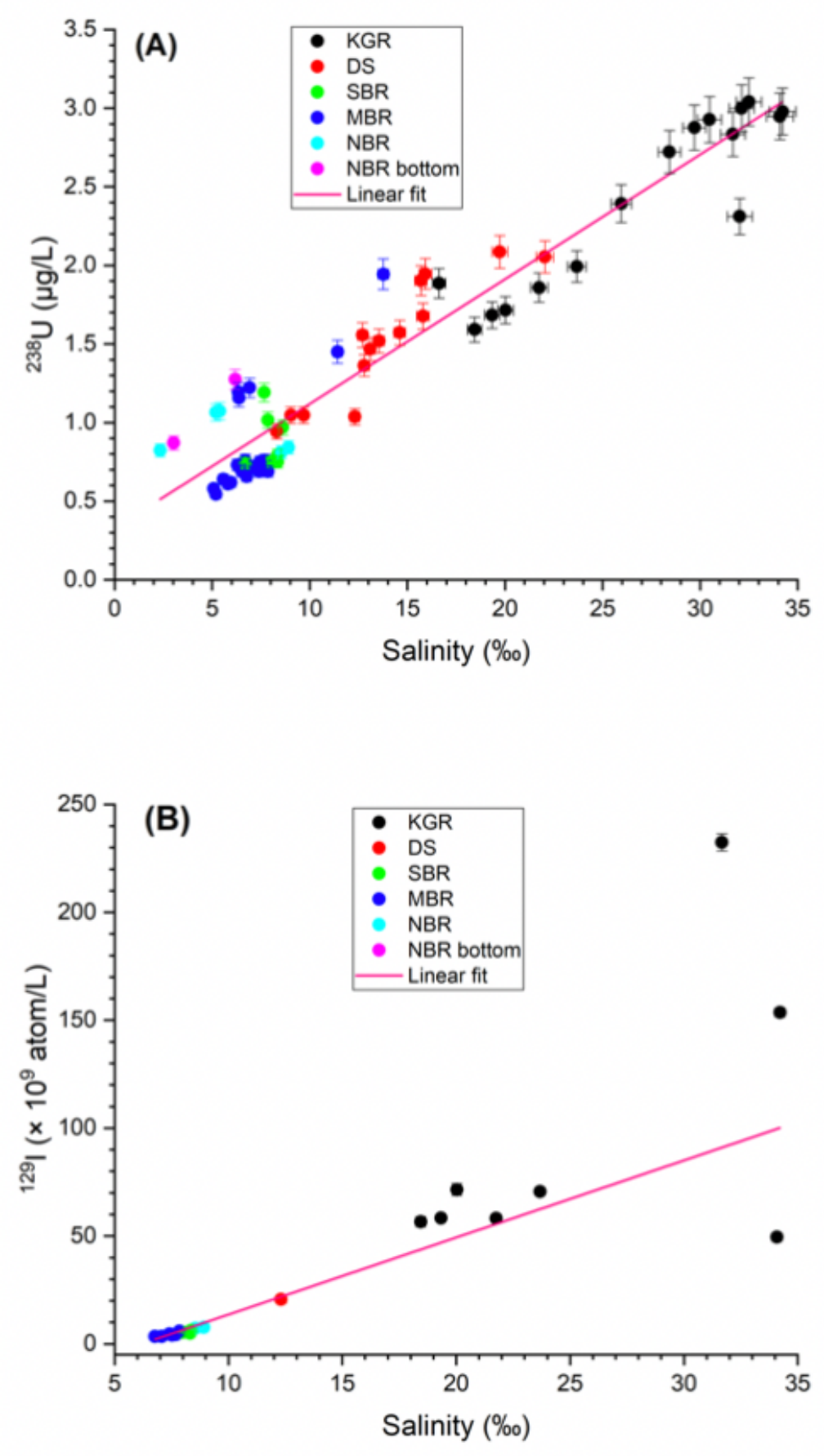

Figure 3

Correlation 238U (A) and 129I (B) concentrations with salinity. (KGR: Kattegat-Skagerrak region including the Jutland west coast nearby the North Sea; DS: Danish Straits including the Belt Seas and the Sound; SBR: South Baltic Sea region including Arkona Basin, Borholm Basin and South Baltic Proper; MBR: 
Middle Baltic Sea region including Northern Baltic Proper, Western Gotland Basin, Eastern Gotland Basin and Gulf of Riga; and NBR: North Baltic Sea region including Archipelago and Åland Sea, Bothnian Sea and Bothnian Bay).
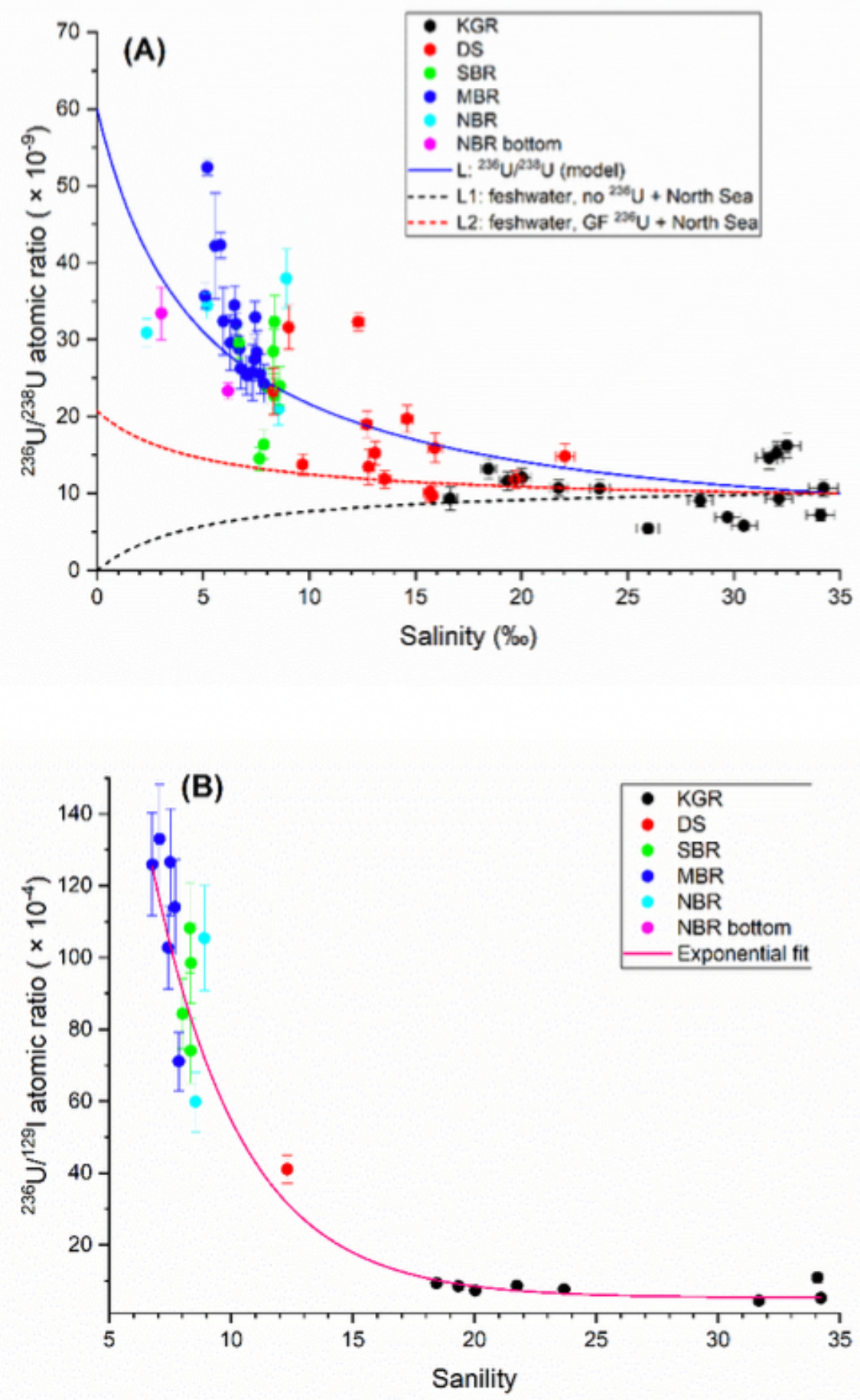

Figure 4

Variation of 236U/238U atomic ratio (A) and 236U/129I ratios (B) with salinity. (KGR: Kattegat-Skagerrak region including the Jutland west coast nearby the North Sea; DS: Danish Straits including the Belt Seas 
and the Sound; SBR: South Baltic Sea region including Arkona Basin, Borholm Basin and South Baltic Proper; MBR: Middle Baltic Sea region including Northern Baltic Proper, Western Gotland Basin, Eastern Gotland Basin and Gulf of Riga; and NBR: North Baltic Sea region including Archipelago and Åland Sea, Bothnian Sea and Bothnian Bay; L (blue solid line): the best-fit binary mixing line between the North Sea water and a freshwater end member with salinity $=0,238 \mathrm{U}=0.4 \mu \mathrm{g} / \mathrm{l}, 236 \mathrm{U} / 238 \mathrm{U}$ atomic ratio $=6 \times 10-8$ and $236 \mathrm{U}=6 \times 107$ atom/L; L1 (black dashed line): the binary mixing line between the North Sea water and an assumed freshwater end member containing no $236 \mathrm{U}$ (salinity $=0,238 \mathrm{U}=0.4 \mu \mathrm{g} / \mathrm{l}, 236 \mathrm{U} / 238 \mathrm{U}$ atomic ratio $=0$ and $236 \mathrm{U}=0 ; \mathrm{L} 2$ (red dashed line): the binary mixing line between the North Sea water and an assumed freshwater end member with salinity $=0,238 \mathrm{U}=0.4 \mu \mathrm{g} / \mathrm{L}, 236 \mathrm{U}=2 \times 107 \mathrm{atom} / \mathrm{L}$, and $236 \mathrm{U} / 238 \mathrm{U}$ atomic ratio $=2 \times 10-8$; the pink solid line: exponential fit of $236 \mathrm{U} / 129 \mathrm{I}$ atomic ratio vs. salinity) 

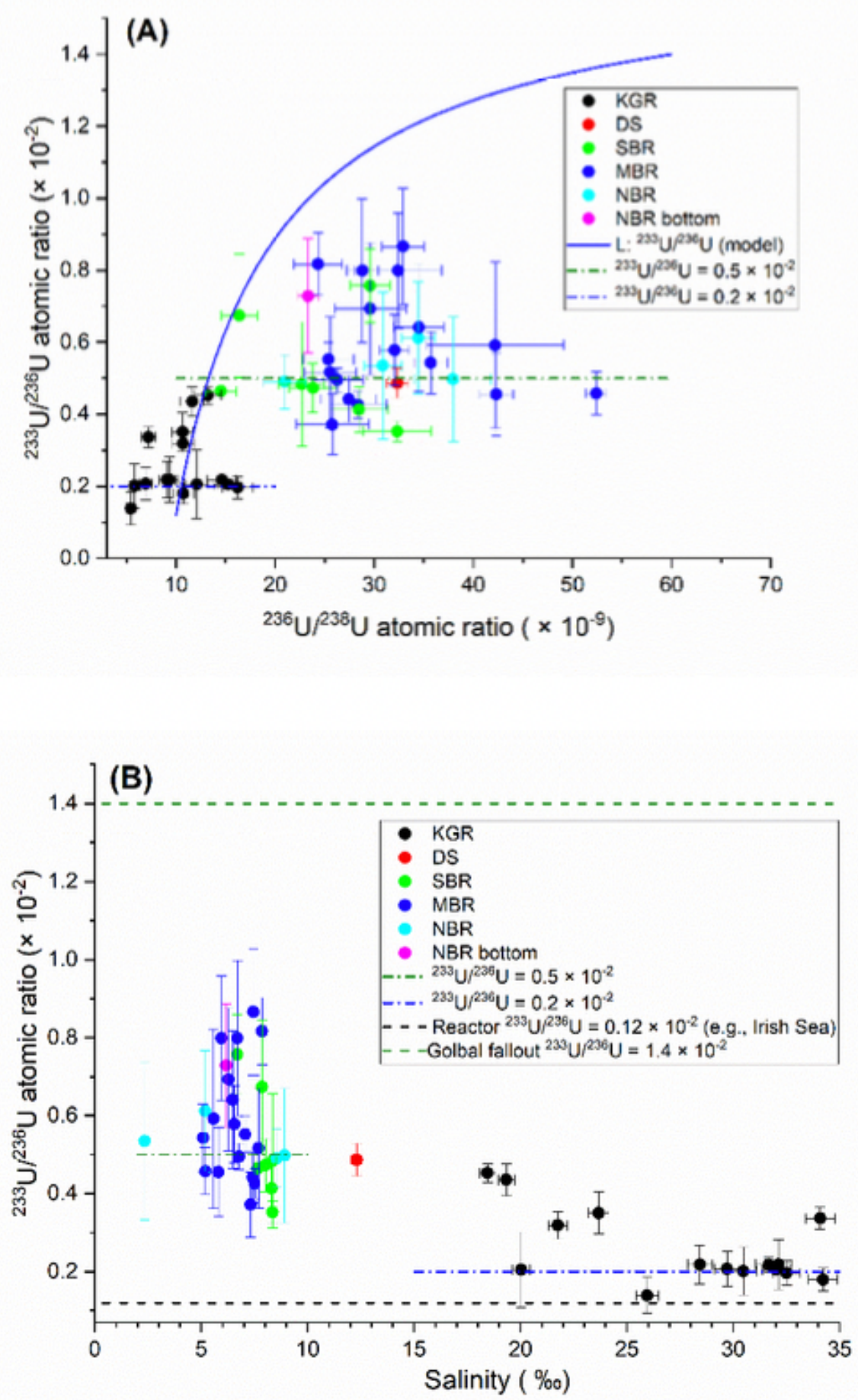

\section{Figure 5}

Variations of $233 \mathrm{U} / 236 \mathrm{U}$ atomic ratio with salinity. (KGR: Kattegat-Skagerrak region including the Jutland west coast nearby the North Sea; DS: Danish Straits including the Belt Seas and the Sound; SBR: South Baltic Sea region including Arkona Basin, Borholm Basin and South Baltic Proper; MBR: Middle Baltic Sea region including Northern Baltic Proper, Western Gotland Basin, Eastern Gotland Basin and Gulf of Riga; and NBR: North Baltic Sea region including Archipelago and Åland Sea, Bothnian Sea and Bothnian Bay; 
L (blue solid line): the best-fit binary mixing line between the North Sea water and a freshwater end member with salinity $=0,238 \mathrm{U}=0.4 \mu \mathrm{g} / \mathrm{l}, 236 \mathrm{U} / 238 \mathrm{U}$ atomic ratio $=6 \times 10-8$ and $236 \mathrm{U}=6 \times 107$ atom/L).

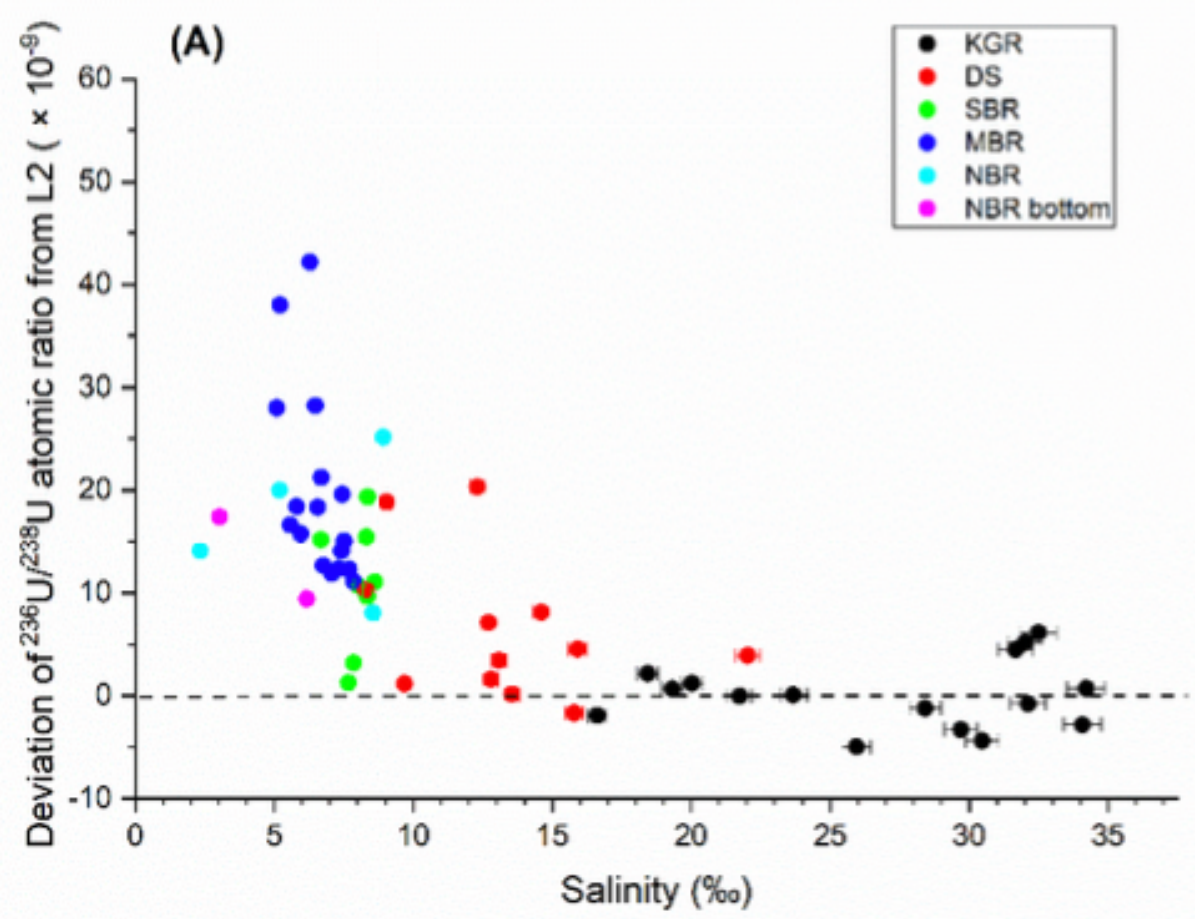

(B) Deviation of ${ }^{236} \mathrm{U} / 238 \mathrm{U}$ atomic ratio from $\mathrm{L2}\left[\times 10^{-9}\right]$

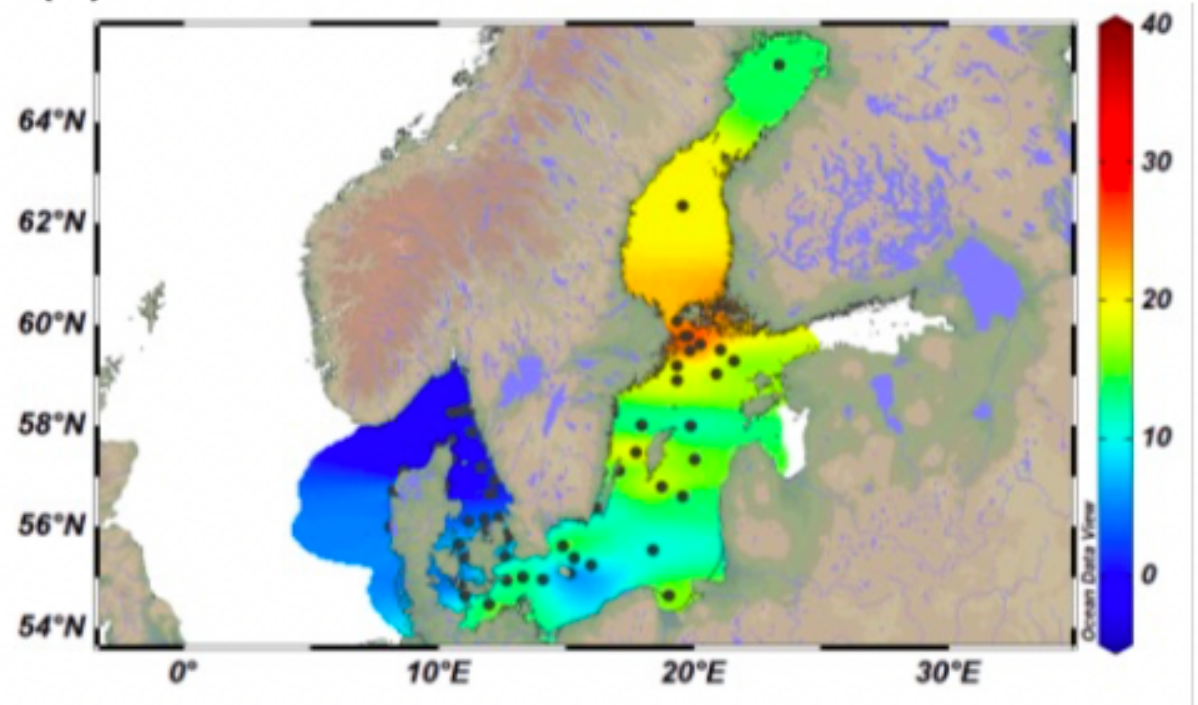

Figure 6

Deviations of $236 \mathrm{U} / 238 \mathrm{U}$ atomic ratio from binary mixing line $\mathrm{L} 2(\mathrm{~A})$ and their respective geographical distribution on the map (B) (L2 refers to the red dashed line in Figure 4A) 


\section{Supplementary Files}

This is a list of supplementary files associated with this preprint. Click to download.

- Supportinginformationfinal.docx 